\title{
Rancang Bangun Web Service Sistem Informasi Keuangan GMIM Wilayah Tomohon 3
}

\author{
Billy Marentek $^{(1)}$, Arie S. M. Lumenta ${ }^{(2)}$, Oktavian A. Lantang ${ }^{(3)}$ \\ Teknik Informatika, Universitas Sam Ratulangi, Manado, Indonesia. \\ Email: bmarentek@yahoo.com ${ }^{(1)}$, al@unsrat.ac.id ${ }^{(2)}$, oktavian@unsrat.ac.id ${ }^{(3)}$
}

\begin{abstract}
Abstrak - Bertambahnya warga Gereja secara terusmenerus menyebabkan pertambahan data yang cukup signifikan pada Gereja-Gereja, baik itu data jemaat, data keuangan dan data-data lainnya. Arus informasi keuangan Gereja sangat dibutuhkan untuk mengetahui perkembangan Gereja dari sisi finansial, bagaimana struktur modal, berapa pemasukan dan pengeluaran pada satu periode tertentu. Pengelolaan data keuangan di GMIM Wilayah Tomohon 3 masih dilakukan dengan cara manual yang kurang efektif dan efiesien sehingga menyebabkan tidak maksimalnya proses pengelolaan data yang ada. Oleh karena itu dibuatlah sebuah aplikasi Web Service Sistem Informasi Keuangan GMIM Wilayah 3 untuk mengatasi permasalahan pengelolaan data keuangan yang ada.
\end{abstract}

Metode pembuatan aplikasi ini menggunakan metode perancangan sistem Rapid Application Development (RAD), yang dimulai dengan tahap analisis persyaratan yang dilakukan dengan membuat problem statement matrix. Tahap selanjutnya, design workshop (pemodelan) digambarkan dengan proses bisnis, structural model dan behavioral model, serta human computer interaction layer design. Tahap terakhir, implementasi (konstruksi) dijelaskan dengan implementasi basis data dan kode sumber program.

Kata Kunci : Gereja, Rapid Application Development (RAD), Sistem Informasi Keuangan, Web Service

Abstract - The continuing increase in Church members leads to significant data increases on the Churches, be it congregational data, financial data and other data. The Church's financial information flow is very needed to know the development of the Church from the financial side, to the structure of capital, how much income and expenditure in a given period. The management of financial data in GMIM Tomohon Region 3 is still done manually which is less effective and efficient thus causing not maximal the existing data management process. Therefore it is made a Web Service Information Financial System of GMIM Region 3 application to overcome the problems of management the existing financial data.

The method of making this application using Rapid Application Development (RAD) system design method, which starts with requirement analysis phase which is done by making problem statement matrix. The next stage, design workshop (modeling) is described with business processes, structural models and behavioral models, and human computer interaction layer design. The last stage, implementation (construction) is explained by the implementation of database and program source code. Keywords : Church, Rapid Application Development (RAD), Financial Information System, Web Service

\section{PENDAHULUAN}

Berkembangnya teknologi di zaman ini, membuat berkembangnya kebutuhan akan informasi yang cepat dan tepat. Berbagai organisasi diharuskan agar dapat beradaptasi dengan perkembangan teknologi di saat ini.
Kebutuhan informasi oleh organisasi-organisasi tersebut semakin bertambah baik untuk organisasi profit maupun non-profit. Bertambahnya warga Gereja secara terusmenerus menyebabkan pertambahan data yang cukup signifikan pada Gereja-gereja, baik itu data jemaat, data keuangan dan data-data lainnya. Selama ini penanganan dan pengolahan data jemaat, data keuangan dan informasi seputar Gereja dilakukan secara manual karena kurangnya pengetahuan dan sarana dan prasarana.

Dengan perkembangan teknologi saat ini, Gerejagereja pun diharuskan memanfaatkan teknologi untuk mengurangi atau bahkan menghilangkan kelambanan, kesulitan dan ketidak-efektifan pengelolaan data secara manual. Berbagai macam teknologi pun sudah dapat diimplementasikan pada pengelolaan data Gereja, terlebih khusus data keuangan Gereja.

Arus informasi keuangan Gereja sangat dibutuhkan untuk mengetahui perkembangan Gereja dari sisi finansial, bagaimana struktur modal, berapa pemasukan dan pengeluaran pada satu periode tertentu. Oleh karena itu, pengelolaan data keuangan yang profesional sudah merupakan tuntutan yang harus dipenuhi untuk dapat melaksanakan kegiatan-kegiatan Gereja dengan baik.

Pengelolaan data keuangan di GMIM Wilayah Tomohon 3 masih dilakukan dengan cara manual. Datadata keuangan Gereja disimpan dalam sebuah worksheet yang kurang efektif dan efisien karena mempunyai keterbatasan yaitu integrasi antar variabel-variabel data yang masih menggunakan hyperlink pada Microsoft Excel yang menyebabkan tidak maksimalnya proses pengelolaan data yang ada.

Berdasarkan hal tersebut, dalam penyusunan skripsi ini penulis mengambil judul "Rancang Bangun Web Service Sistem Informasi Keuangan GMIM Wilayah Tomohon 3".

\section{TINJAUAN PUSTAKA}

\subsection{Sistem Informasi}

Menurut Jogianto, sistem informasi adalah suatu sistem di dalam suatu organisasi yang mempertemukan kebutuhan pengolahan transaksi harian yang mendukung fungsi operasi organisasi yang bersifat manajerial dengan kegiatan strategi dari suatu organisasi untuk dapat menyediakan kepada pihak luar tertentu dengan laporan-laporan yang diperlukan ${ }^{[1]}$. Sistem informasi merupakan suatu perkumpulan data yang terorganisasi beserta tatacara penggunaannya yang mencangkup lebih jauh dari pada sekedar penyajian.

Berdasarkan hal-hal tersebut,, dapat disimpulkan bahwa sistem informasi adalah sekumpulan prosedur organisasi yang dilaksanakan untuk mencapai suatu 
tujuan yang memberikan informasi bagi pengambil keputusan dan untuk mengendalikan organisasi.

\subsection{Sistem Informasi Keuangan}

Sistem informasi keuangan adalah sistem informasi yang dirancang untuk menyediakan informasi kepada orang atau kelompok (user) baik dalam maupun di luar instansi mengenai arus keuangan serta permasalahannya di instansi tersebut ${ }^{[2]}$. Sistem informasi keuangan merupakan sistem informasi yang digunakan guna mengatur keuangan yang ada dalam organisasi maupun instansi.

\subsection{Web Service}

Menurut Snell, web service adalah interface jaringan yang dapat diakses pada fungsionalitas sebuah aplikasi, dan dibangun menggunakan teknologi standar internet ${ }^{[3]}$. Sedangkan menurut Chappel, web service adalah sekumpulan logika bisnis yang dapat diakses dengan protokol internet standar seperti $\mathrm{HTTP}^{[4]}$. Web service dapat diartikan sebagai metode pertukaran data (database), perangkat lunak (software) atau bagian dari perangkat lunak yang melaksanakan suatu proses tertentu yang terletak pada server yang terkoneksi dengan jaringan (internet) yang dapat diakses dengan protokol internet (HTTP). Web service mampu menunjang interoperabilitas, sehingga web service dapat memudahkan integrasi berbagai macam sistem. Seperti yang dijelaskan oleh World Wide Web Consortium (W3C), web service menyediakan sebuah standar operasi antara perangkat lunak yang berjalan di berbagai macam platform dan frameworks. Contoh implementasi dari web service antara lain adalah Simple Object Access Protocol (SOAP) dan REpresentasional State Transfer (REST).

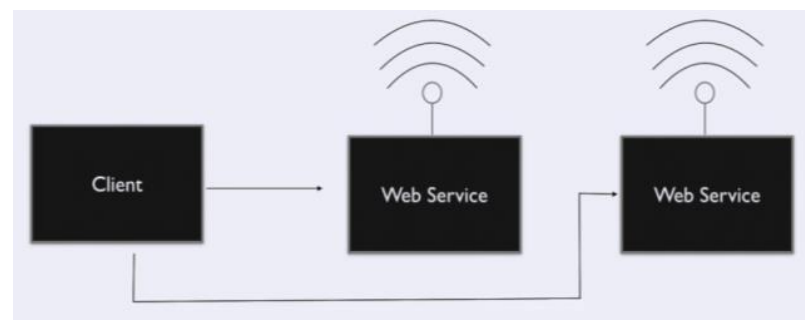

Gambar 1. Model Sederhana Web Service

\subsection{Representasional State Transfer (REST) Web Service}

REST web service / RESTful web service adalah sebuah standar arsitektur komunikasi berbasis web yang sering diterapkan dalam pengembangan layanan berbasis web $^{[5]}$. REST web services menggunakan protokol HTTP untuk pertukaran data. Cara kerja REST web service adalah REST server menyediakan jalur akses terhadap resource (sumber daya/data), sedangkan REST client melakukan akses kepada resource tersebut untuk ditampilkan atau digunakan lebih lanjut. Setiap resource diidentifikasi oleh URIs (Universal Resource Identifiers) atau global ID. Proses pengalamatan data pada website umumnya yang merupakan pengalamatan action-based URL, sedangkan pengalamatan data pada REST merupakan resource-based URI (URI berbasis sumber daya). Resource tersebut kemudian dapat direpresentasikan dalam bentuk format teks, JSON atau XML. Format yang umum digunakan adalah JSON dan XML.

\subsection{JavaScript Object Notation (JSON)}

JSON adalah format pertukaran data yang ringan, mudah dibaca dan ditulis oleh manusia, serta mudah diterjemahkan dan dibuat (generate) oleh computer ${ }^{[6]}$. JSON merupakan format teks yang tidak bergantung pada bahasa pemprograman apapun karena menggunakan gaya bahasa yang umum digunakan oleh programmer keluarga $\mathrm{C}$ termasuk $\mathrm{C}, \mathrm{C}++, \mathrm{C}$, Java, JavaScript, Perl, Python dll.

\subsection{Gereja}

Gereja (bahasa Portugis: igreja dan bahasa Yunani:

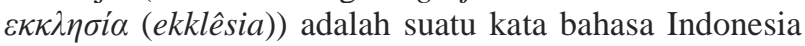
bahasa Indonesia yang berarti suatu perkumpulan atau

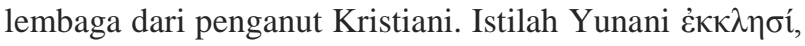
yang muncul dalam Perjanjian Baru di Alkitab Kristen biasanya diterjemahkan sebagai "jemaat".

\subsection{Gereja Masehi Injili di Minahasa (GMIM)}

Gereja Masehi Injili di Minahasa adalah salah satu kelompok Gereja Protestan di Indonesia yang beraliran Calvinisme $^{[7]}$. GMIM didirikan di Minahasa, Sulawesi Utara pada tahun 1934 setelah dipisahkan dari Gereja induknya, "Indische Kerk" (yang sekarang menjadi Gereja Protestan di Indonesia/GPI) dan pada tanggal 30 September 1934 GMIM dinyatakan sebagai Gereja mandiri. Tanggal ini diperingati sebagai hari jadi GMIM.

\subsection{Rapid Application Development (RAD)}

RAD merupakan model proses perangkat lunak yang menekankan pada daur pengembangan hidup yang singkat. RAD merupakan versi adaptasi cepat dari model waterfall, dengan menggunakan pendekatan konstruksi komponen $^{[8]}$.

Terdapat tiga fase dalam RAD yang melibatkan penganalisis dan pengguna dalam tahap penilaian, perancangan, dan penerapan. Adapun ketiga fase tersebut adalah requirements planning (perencanaan syarat-syarat), RAD design workshop (workshop desain $\mathrm{RAD}$ ), dan implementation (implementasi).

Sesuai dengan metodologi RAD $^{[9]}$, berikut ini adalah tahap-tahap pengembangan aplikasi dari tiap-tiap fase pengembangan aplikasi.

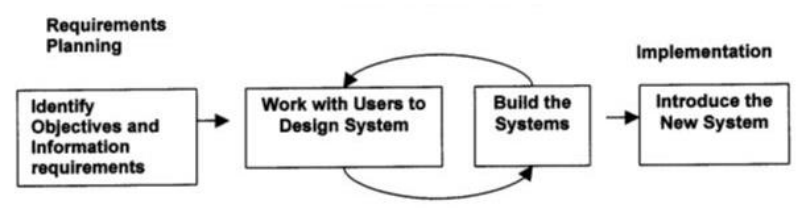

Gambar 2. Tahapan-tahapan RAD

Tahapan RAD terdiri dari 3 fase, yaitu:

1. Requirements Planning (Perencanaan Persyaratan), yaitu:

a. Pengguna dan analis bertemu untuk mengidentifikasi tujuan dari aplikasi atau sistem.

b. Berorientasi pada pemecahan masalah bisnis. 
2. Design Workshop, yaitu:

a. Fase desain dan menyempurnakan.

b. Gunakan kelompok pendukung keputusan sistem untuk membantu pengguna setuju pada desain.

c. Programmer dan analis dapat membangun dan menunjukkan representasi visual dari desain dan alur kerja pengguna.

d. Pengguna menanggapi prototipe kerja aktual.

e. Analis menyempurnakan modul dirancang berdasarkan tanggapan pengguna.

3. Implementation (Penerapan), yaitu:

a. Sebagai sistem yang baru dibangun, sistem baru atau sistem parsial diuji dan diperkenalkan kepada organisasi.

b. Ketika membuat sistem baru, tidak perlu untuk menjalankan sistem yang lama secara parallel.

\subsection{MySQL}

MySQL adalah sebuah program database server yang mampu menerima dan mengirimkan datanya dengan sangat cepat, multi user serta menggunakan perintah standar SQL (Structured Query Language) ${ }^{[10]}$.

\section{METODOLOGI PENELITIAN}

Metodologi penelitian pada penelitian ini menggunakan pendekatan Rapid Application Development (RAD) sehingga fase penelitian yang dilakukan mengikuti tahap-tahap yang ada dalam metodologi RAD yaitu, Analisis Persyaratan, Design Workwshop (Pemodelan) dan Implementasi (Konstruksi).

\subsection{Analisis Persyaratan}

Tahapan ini bertujuan untuk mengidentifikasi kebutuhan, batasan dan objektifitas dari sistem yang akan dibangun dengan mengumpulkan data dari stakeholder. Tahapan ini dilakukan dengan melakukan wawancara terhadap majelis jemaat di GMIM Getsemani Lansot, Oktavian Lantang, ST, MTI mengenai kebutuhan sistem yang dibutuhkan. Setelah melakukan wawancara, maka didapatkan solusi mengenai spesifikasi aplikasi Web Service Sistem Informasi Keuangan GMIM Wilayah Tomohon 3.

\subsection{Design Workshop (Pemodelan)}

Tahapan ini bertujuan untuk merancang semua kegiatan dalam arsitektur sistem secara keseluruhan dengan melibatkan identifikasi dan deskripsi abstraksi sistem perangkat lunak yang mendasar dan hubunganhubungannya agar dapat merancang semua kegiatan dalam arsitektur sistem secara keseluruhan. Tahap ini juga bertujuan untuk meningkatkan pemahaman atas masalah berdasarkan analisis-analisis yang dilakukan. Fase ini digambarkan dengan deskripsi proses bisnis, structural model dan behavioral model, serta human computer interaction layer design.

Hasil dari tahapan ini dapat dilihat pada gambargambar dibawah ini.

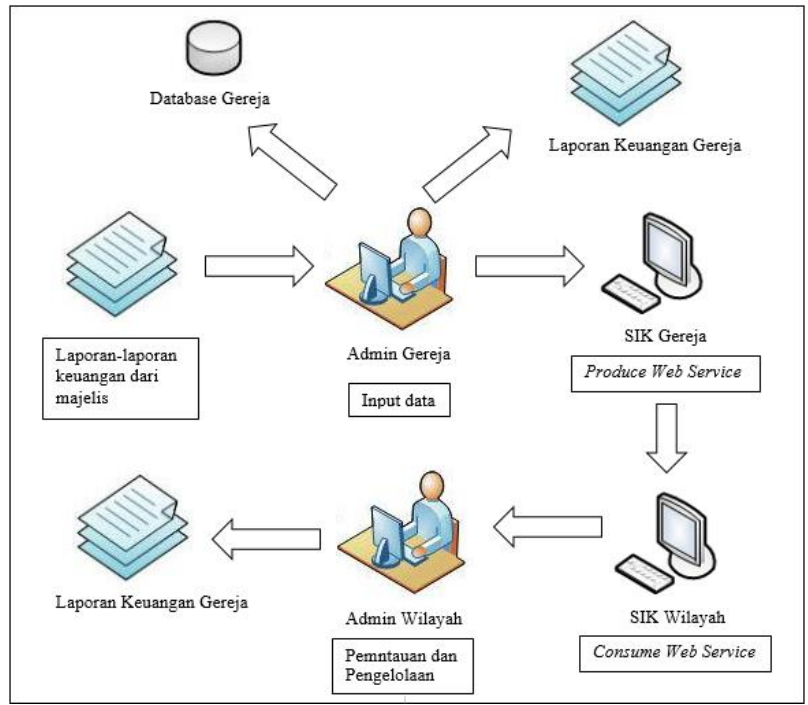

Gambar 3. Proses Bisnis diagram

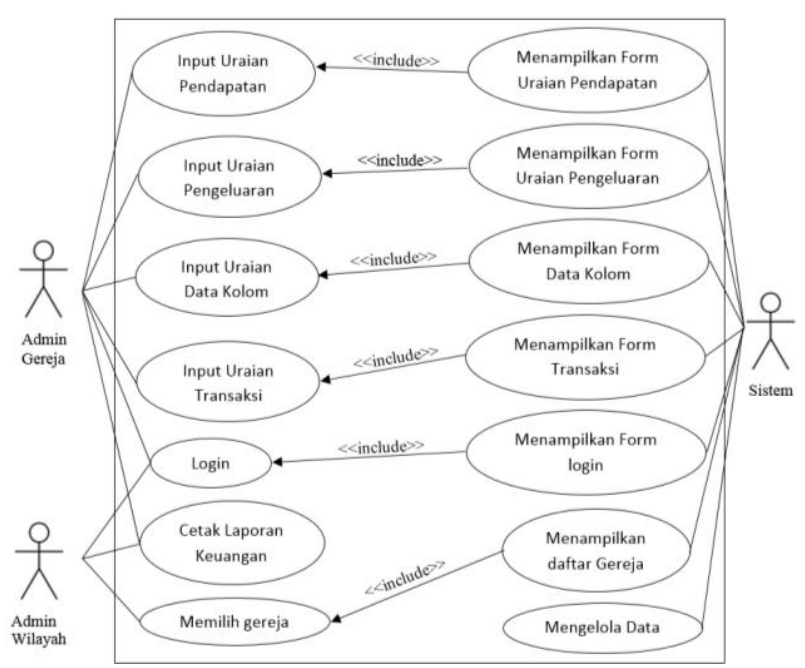

Gambar 4. Use case diagram

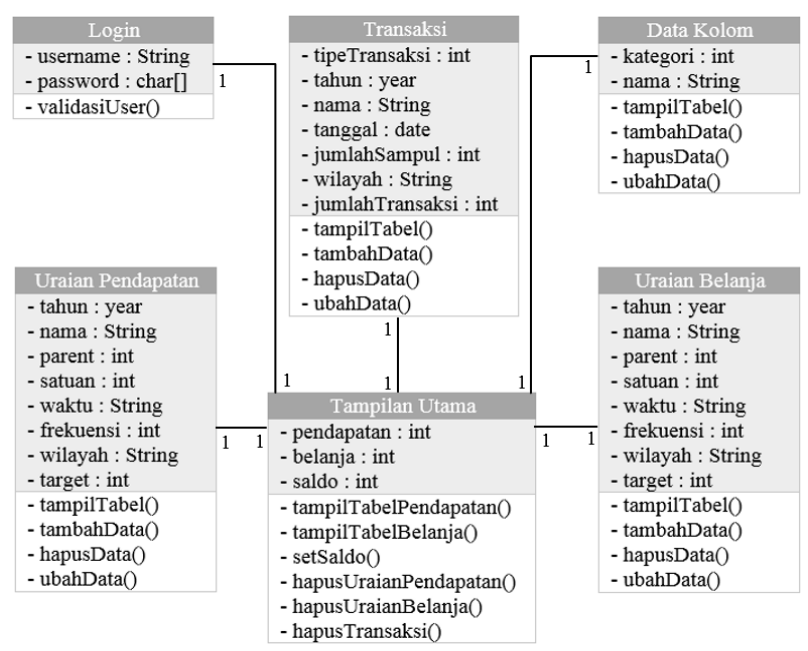

Gambar 5. Class diagram server side (gereja) 


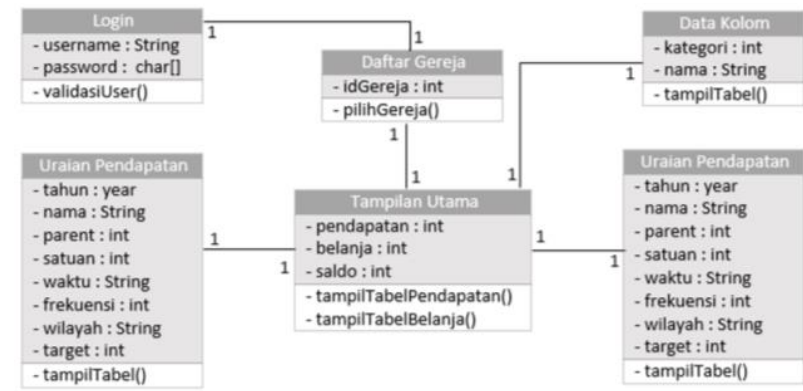

Gambar 6. Class diagram client side (wilayah)

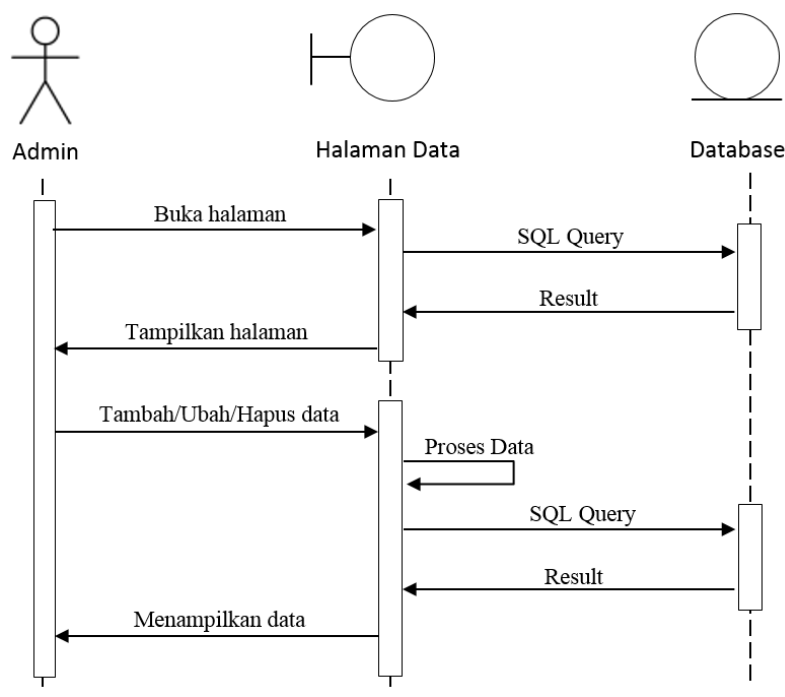

Gambar 7. Sequence diagram manajemen data

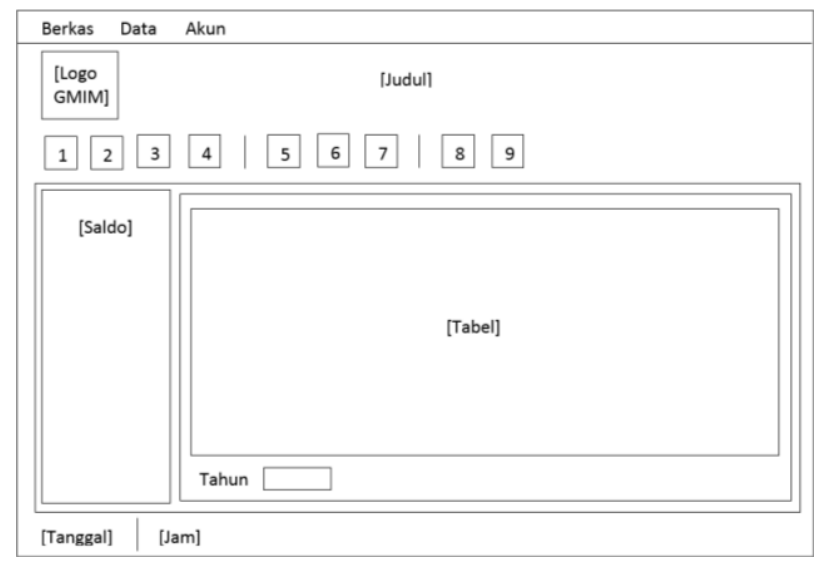

Gambar 8. Storyboard tampilan utama

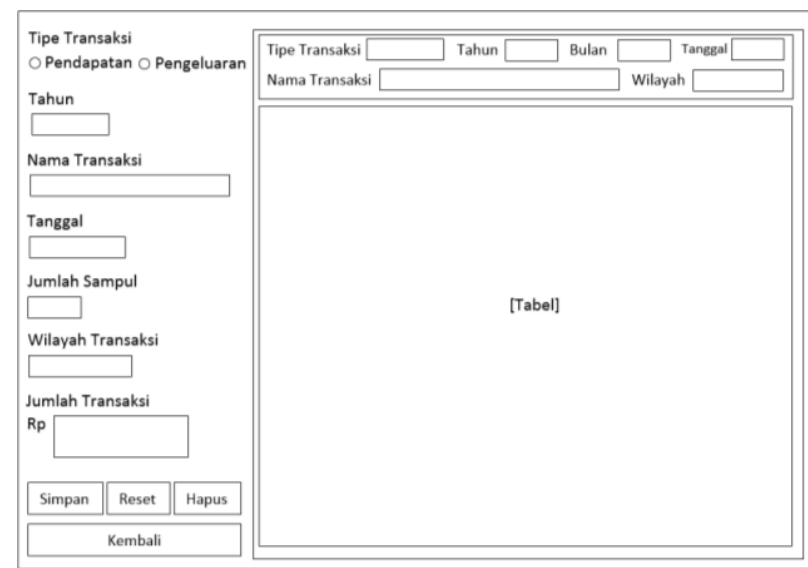

Gambar 9. Storyboard transaksi

\subsection{Implementasi (Konstruksi)}

Tujuan dari tahapan ini adalah untuk mengkonstruksi sistem dan penerapan metode yang diadaptasikan dengan proses seleksi dalam pemrograman terhadap hasil analisa kebutuhan sistem dan akan dijelaskan dalam tahap implemantasi basis data dan kode sumber program. Pada tahap ini programmer menentukan lingkungan implementasi perangkat lunak, perancangan database dan proses kodifikasi. Diagram hasil skema database pada tahap ini dapat dilihat pada gambar berikut.

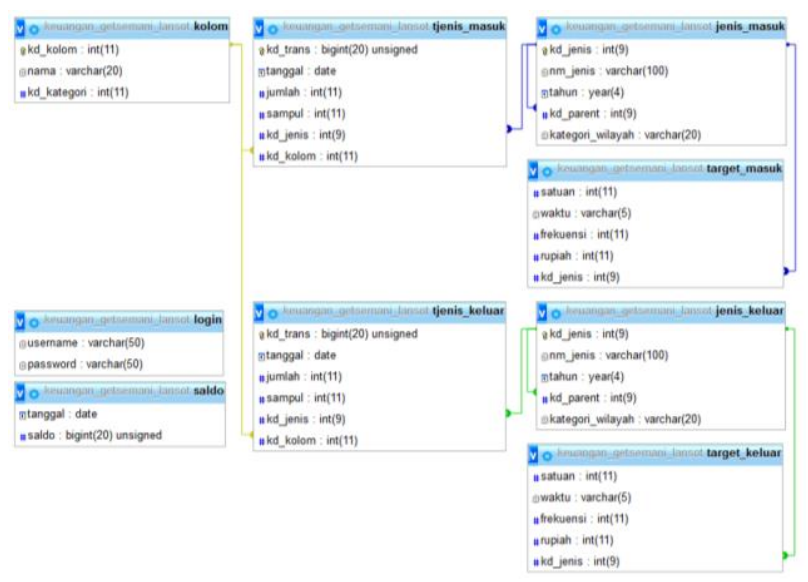

Gambar 10. Skema tabel database

Proses kodifikasi pada sistem ini dilakukan dengan membuat 3 project java pada Netbeans. Project-project tersebut adalah SIKGetsemaniLansot sebagai server side yang mengolah data-data di masing-masing gereja, project selanjutnya adalah SIKGereja sebagai web service dari sistem informasi keuangan gereja yang melakukan proses produce web service, dan project terakhir adalah SIKWilayah sebagai client side yang melakukan consume pada web service yang disediakan oleh gereja-gereja.

\section{IV.HASIL DAN PEMBAHASAN}

Bagian ini menunjukkan hasil dari proses perancangan Web Service Sistem Informasi Keuangan GMIM Wilayah Tomohon 3 yang telah sesuai dengan analisa dan pemodelan yang dilakukan.

Pertama-tama aplikasi akan menunjukkan tampilan Login seperti pada gambar dibawah ini.

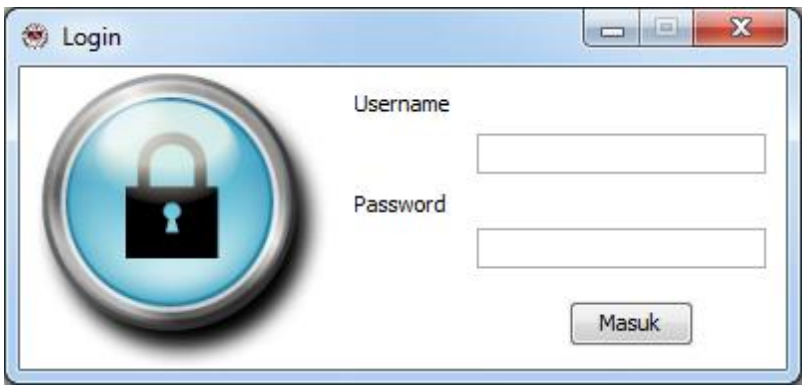

Gambar 11. Tampilan Login

Khusus untuk client side (wilayah) jika admin berhasil masuk, maka akan menampilkan tampilan berikut. 


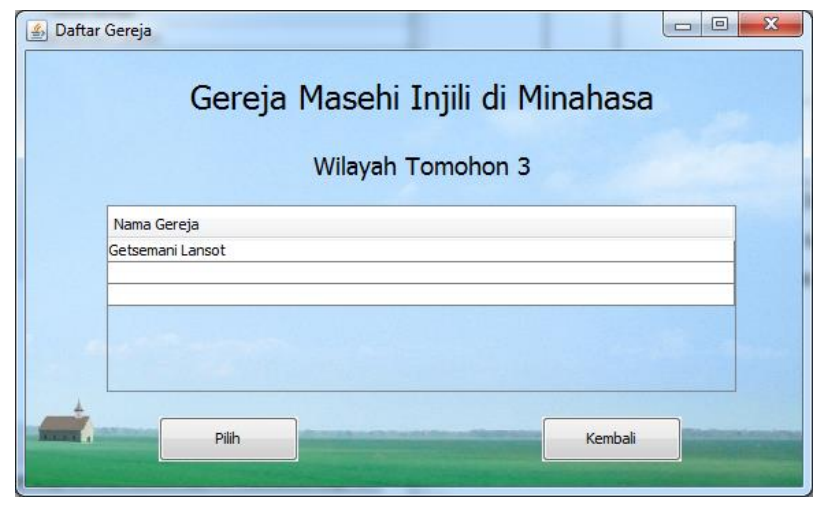

Gambar 12. Tampilan pilih Gereja

Setelah memilih gereja yang akan dilihat, maka aplikasi akan menampilkan tampilan utama seperti dibawah:

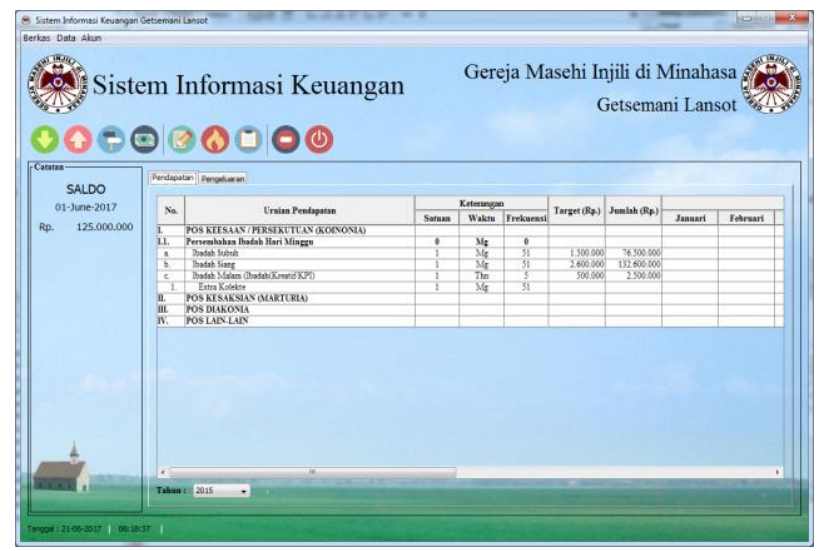

Gambar 13. Tampilan Utama

Pada tampilan ini, admin dapat melihat rekapitulasi keuangan baik pendapatan maupun pengeluaran selama 1 tahun. Tahun yang akan ditampilkan pada tabel, bisa diganti pada combobox yang ada pada tampilan utama. Terdapat juga saldo yang akan selalu diperbaharui setiap tanggal 1. Pada tampilan utama juga terdapat bar navigasi untuk menuju ke tampilan uraian pendapatan/pengeluaran, data kolom, transaksi dan menu cetak. Ada juga menu bar yang memiliki tugas yang sama seperti pada bar navigasi.

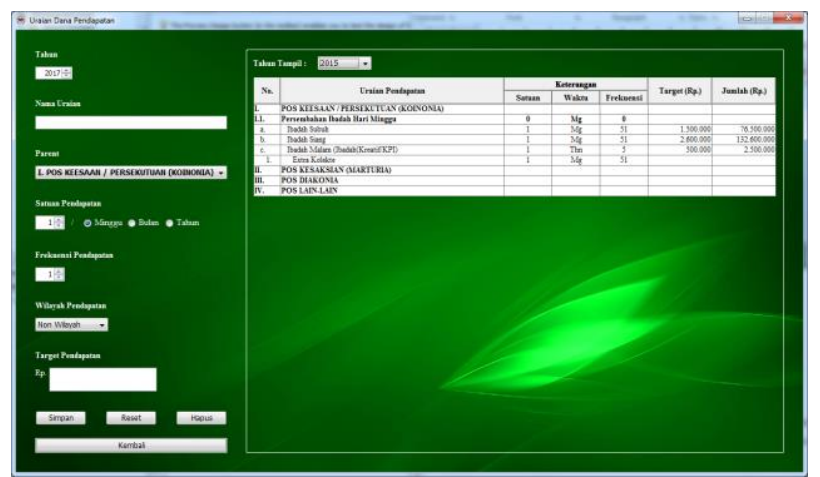

Gambar 14. Tampilan Uraian Data Pendapatan

Tampilan Uraian Data Pendapatan menunjukkan uraian-uraian pendapatan yang ada dan untuk menambah uraian data, menghapus dan mengubah data yang sudah ada. Pada tampilan ini, terdapat tabel yang menunjukkan semua uraian pendapatan yang ada dan sebuah combobox tahun tampil untuk mengganti tahun uraian yang akan ditampilkan di dalam tabel. Pada tampilan di atas, terdapat spinner tahun untuk menambah atau mengubah uraian pendapatan, textbox nama uraian yang akan ditambah, combobox parent yang digunakan untuk menunjukkan apakah uraian yang diisi merupakan bagian dari uraian lainnya. Spinner satuan pendapatan yaitu jumlah satuan pendapatan per rentang waktu yang dapat dipilih melalui radio button minggu, bulan dan tahun. Spinner frekuensi digunakan untuk memasukkan frekuensi pendapatan per tahun. Combobox wilayah pendapatan digunakan untuk menentukan wilayah pendapatan dari uraian yang diolah (kolom, BIPRA dsb). Target pendapatan digunakan untuk mengisi target pendapatan dari uraian selama setahun. Di bagian bawah tampilan, terdapat tombol Simpan untuk menyimpan hasil inputan, Reset untuk mereset inputan-inputan yang sudah diisi, Hapus untuk menghapus uraian yang dipilih di tabel, dan Kembali untuk kembali ke tampilan utama.

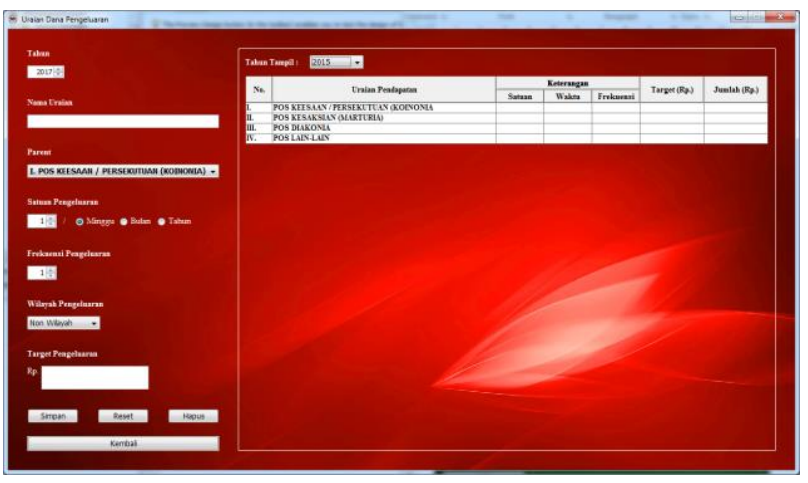

Gambar 15. Tampilan Uraian Data Pengeluaran

Tampilan Uraian Data Pengeluaran menunjukkan uraian-uraian pengeluaran yang ada dan untuk menambah uraian data, menghapus dan mengubah data yang sudah ada. Tampilan uraian pengeleuaran memiliki tampilan yang sama dengan tampilan uraian pendapatan, perbedaannya hanyalah data-data yang diinput, diubah ataupun dihapus adalah data-data dari uraian pengeluaran.

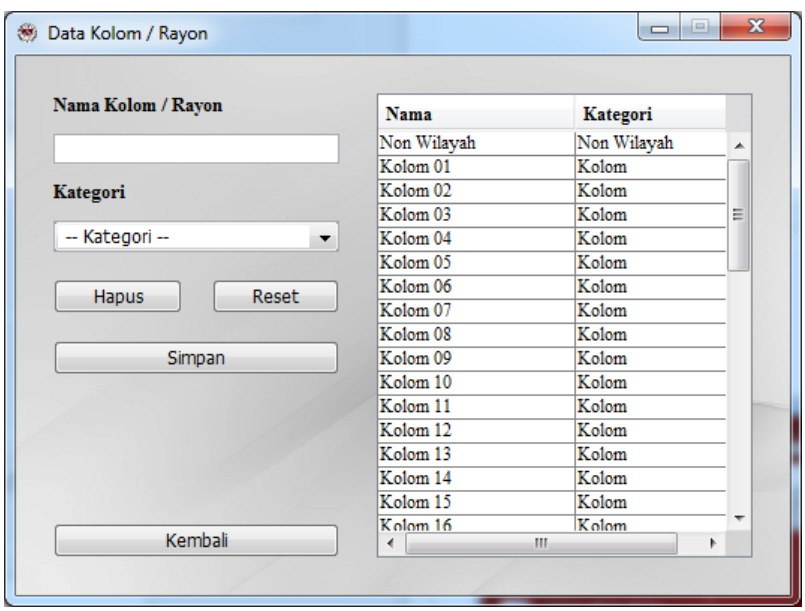

Gambar 16. Tampilan Data Kolom / Rayon

Tampilan data kolom/rayon berfungsi untuk menginput data kolom dan/atau rayon pada sebuah gereja. Pada tampilan ini, terdapat tabel yang menunjukkan data-data 
kolom ataupun rayon yang telah diisi. Pada bagian kiri tampilan, terdapat textbox nama kolom/rayon yang akan diisi, textbox kategori yang merupakan kategori dari nama yang diisi (mis: Kolom, PKB dsb), button hapus bertujuan untuk menghapus data yang dipilih dari tabel, button reset bertujuan untuk mereset form isian yang telah diisi, button simpan bertujuan untuk menyimpan hasil dari inputan dan button kembali yang akan mengembalikan program ke menu utama.

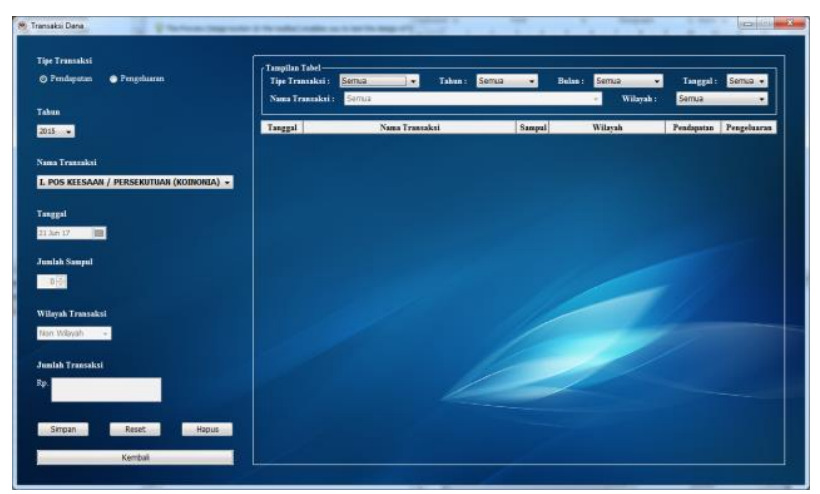

Gambar 17. Tampilan Transaksi Dana

Tampilan transaksi dana berfungsi untuk menambah, menghapus, dan mengubah data-data transaksi. Pada bagian kiri, terdapat 2 buah radio button yang berfungsi untuk memilih jenis transaksi yang akan dilakukan. Selanjutnya ada combobox tahun untuk memilih tahun transaksi. Combobox nama transaksi berfungsi untuk memilih nama uraian dari transaksi yang akan dilakukan. Datechooser berguna untuk memilih tanggal transaksi, spinner jumlah sampul berfungsi untuk menentukan jumlah sampul yang ada pada setiap transaksi. Combobox wilayah transaksi berfungsi untuk menentukan wilayah transaksi yang akan dilakukan. Selanjutnya textbox transaksi berfungsi untuk menentukan jumlah transaksi yang akan dilakukan. Empat buah button yang masing-masing adalah, button simpan untuk menyimpan data transaksi yang telah diisi, button reset untuk mereset form isian yang telah diisi, button hapus untuk menghapus data transaksi yang telah dipilih dari tabel dan button kembali untuk kembali menuju tampilan utama. Pada bagian kanan terdapat tabel transaksi yang telah ada. Di bagian atasnya terdapat pilihan untuk mengatur tampilan tabel. Combobox tipe transaksi untuk menentukan tipe transaksi yang akan ditampilkan didalam tabel (semua data, pendapatan atau pengeluaran). Tiga buah combobox selanjutnya adalah combobox tahun, bulan dan tanggal untuk menentukan tahun/bulan/tanggal yang akan ditampilkan pada tabel. Combobox uraian bertujuan jika ingin menampilkan pada tabel data transaksi sebuah uraian tertentu. Dan terakhir ada combobox wilayah jika ingin menampilkan pada tabel data transaksi sebuah wilayah tertentu.

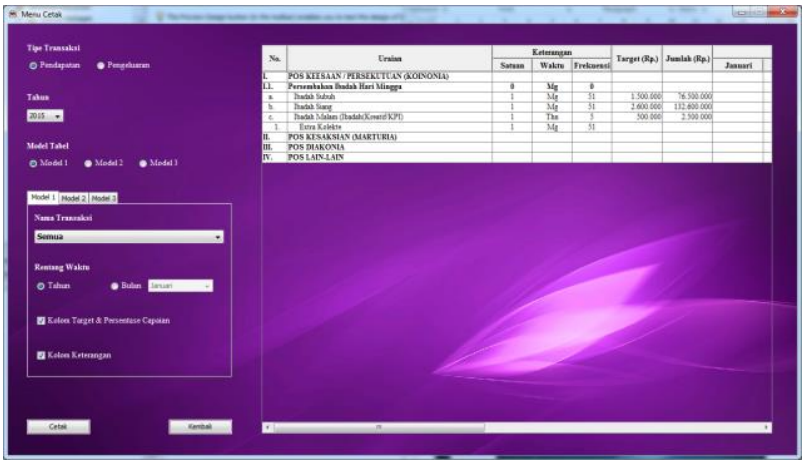

Gambar 18. Tampilan Menu Cetak

Tampilan cetak berfungsi untuk mencetak laporan keuangan berdasarkan model atau format yang diinginkan pengguna. Pada bagian kanan tampilan, terdapat sebuah tabel yang menunjukan bagaimana tampilan dari tabel yang akan dicetak. Pada bagian kiri tabel terdapat radio button untuk memilih tipe transaksi yang akan dicetak, setelah itu terdapat juga combobox tahun laporan yang berfungsi untuk menentukan tahun laporan keuangan yang akan dicetak. Selanjutnya terdapat tiga buah radion button dan 3 panel yang disatukan dalam sebuah tabbed panel yang berfungsi untuk memilih dan mengatur model dari tabel yang akan dicetak. Model 1 dapat mencetak laporan keuangan dalam rentang waktu 1 tahun ataupun 1 bulan serta pengguna dapat memilih jika ingin menyertakan kolom target dan persentase capaian pertahun dan kolom keterangan yang berisi satuan, waktu dan frekuensi pendapatan pada tabel. Pengaturan ini dapat dilakukan di dalam tabbed panel Model 1. Model 2 dapat mencetak gabungan data laporan keuangan dalam rentang waktu 1 bulan per wilayah transaksi. Model 3 dapat mencetak rincian data laporan keuangan dalam rentang waktu 1 bulan per wilayah transaksi.

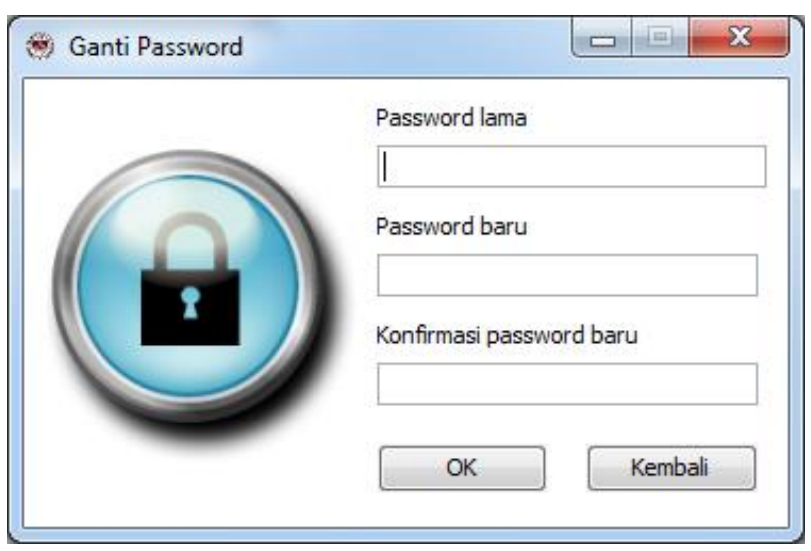

Gambar 19. Tampilan Ganti Password 
Tampilan ganti password berfungsi untuk mengganti password admin. Pada Gambar 3.18 dapat dilihat bahwa tampilan ganti password memiliki 3 buah password field. Password field pertama berfungsi sebagai isian password lama dari admin, password field kedua berfungsi sebagai isian password baru dan password field ketiga berfungsi untuk mengkonfirmasi password yang baru agar tidak ada kesalahan penulisan. Setelah itu terdapat button OK untuk menyimpan perubahan dan button kembali untuk kembali ke tampilan utama.

\section{PENUTUP}

\subsection{Kesimpulan}

Berdasarkan penelitian yang telah dilakukan dalam membangun web service sistem informasi keuangan GMIM Wilayah Tomohon 3, dapat ditarik kesimpulan antara lain :

1. Sebuah standar Sistem Informasi keuangan dapat menyelesaikan permasalahan beragamnya bentuk laporan keuangan gereja.

2. Web service Sistem Informasi Keuangan GMIM Wilayah Tomohon 3, dapat menyediakan informasi secara digital dan terintegrasi antara gereja-gereja dengan kantor wilayahnya.

\subsection{Saran}

Berdasarkan hasil penelitian dan kesimpulan mengenai web service sistem informasi keuangan GMIM Wilayah Tomohon 3, maka diajukan saran sebagai berikut:

1. Sistem informasi keuangan dapat melakukan tugas dengan tipe-tipe data yang lebih kompleks seperti foto, video dan suara.

2. Penelitian terhadap pengembangan dan implementasi Web Service sistem informasi keuangan disarankan untuk dilanjutkan dengan aspek penelitian lainnya dalam kajian yang lebih luas, seperti mengintegrasikan web service dengan website gereja dan dapat diakses dalam berbagai bentuk media seperti melalui browser ataupun gadget.

\section{DAFTAR PUSTAKA}

[1] Hartono, Jogianto. 2005. "Sistem Teknologi Informasi Edisi II'. Andi Offset. Yogyakarta.

[2] Wulansari, Nurita, Purnama, Bambang Eka, dan Wardati, Indah Uly. 2013. "Sistem Informasi Pengelolaan Keuangan Sekolah Pada Sekolah Menengah Kejuruan (SMK) Pgri 1 Pacitan". Indonesian Journal of Network \& Security. Vol 4, No 3. http://ijns.org/journal/index.php/ijns/article/ view/185/ 180. 12 Juni 2017.

[3] Snell, J. 2001. "Programming Web Services with SOA'. O’Reilly. California.

[4] Chappel, David A., Jewell, Tyler. 2002. "Java Web Services", O’Reilly \& Associates Inc. California.

[5] Codepolitan. "Mengenai RESTful Web Service" [Internet]. 25 Februari 2016 [dikutip 12 Juni 2017]. Tersedia dari: https://www.codepolitan.com/ mengenal-restful-web-services.

[6] JSON. "Pengenalan JSON" [Internet]. [dikutip 12 Juni 2017]. Tersedia dari: http://json.org/jsonid.html.
[7] Gereja Masehi Injili di Minahasa. "Sejarah Singkat GMIM" [Internet]. [dikutip 12 Juni 2017]. Tersedia dari: https://www.gmim.or.id/sejarah-singkatgmim/.

[8] Pressman, S, Roger, Ph.D. 2010. "Rekayasa Perangkat Lunak Pendekatan Praktisi Edisi 7 (Buku 1)". Andi. Yogyakarta.

[9] Kendall, J.E. \& Kendall, K.E. 2010. “Analisis dan Perancangan Sistem". Penerbit Indeks. Jakarta.

[10] Bunafit, Nugroho. 2004. "PHP dan MySQL dengan editor Dreamweaver $M X$ ”. Andi Yogyakarta. Yogyakarta.

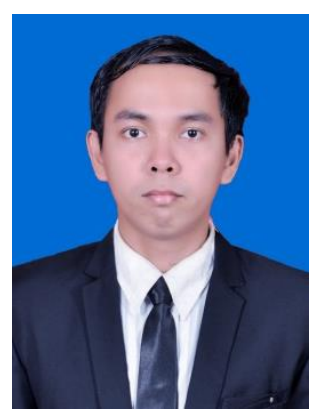

Sekilas tentang penulis. Penulis bernama lengkap Billy Marentek, anak pertama dari tiga orang bersaudara. Lahir di Manado pada tanggal 12 Oktober 1993.

Saya mulai menempuh pendidikan di Sekolah Dasar Negeri 116 (1998-2004). Setelah itu saya melanjutkan ke Sekolah Menengah Pertama Katolik Pax Christi (2004-2007). Selanjutnya saya melanjutkan ke Sekolah Menengah Atas Negeri 1 Manado (2007-2010).

Setelah itu di Tahun 2010 saya melanjutkan pendidikan ke salah satu perguruan tinggi yang berada di Manado yaitu Universitas Sam Ratulangi Manado, dengan mengambil program studi S1 Teknik Informatika di Jurusan Elektro Fakultas Teknik. 